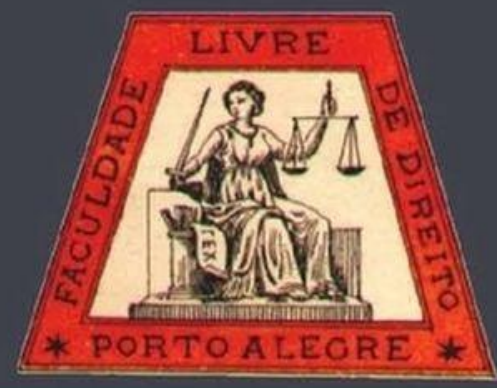

\title{
Sobre uma política criminal baseada na teoria do direito penal do inimigo
}

Criminal policy based on the theory of criminal law of the enemy

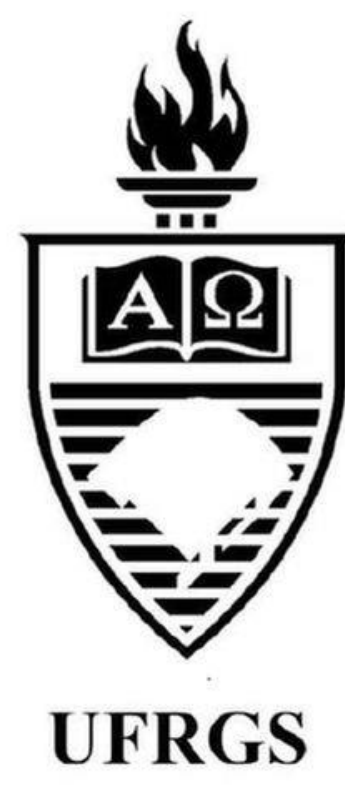

Davi de Paiva Costa Tangerino

Universidade Estadual do Rio de Janeiro

Henrique Olive

Universidade Estadual do Rio de Janeiro 


\title{
Sobre uma política criminal baseada na teoria do direito penal do inimigo
}

\author{
Criminal policy based on the theory of criminal law of the enemy
}

Davi de Paiva Costa Tangerino*

Henrique Olive ${ }^{* *}$

\section{REFERÊNCIA}

TANGERINO, Davi de Paiva Costa; OLIVE, Henrique. Sobre uma política criminal baseada na teoria do direito penal do inimigo. Revista da Faculdade de Direito da UFRGS, Porto Alegre, n. 39, p. 225-239, dez. 2018.

\section{RESUMO}

Esta apresentação tem por objetivo discutir os instrumentos e problemas relacionados a implementação de uma política criminal baseada em pressupostos da teoria do direito penal do inimigo, desenvolvida mais detalhadamente por Günter Jakobs. Com isto, discute-se tanto a viabilidade, como os limites práticos da atuação do Estado no reconhecimento e na neutralização de riscos. Ainda, abordam-se os pontos elementares da teoria, além de debater as diversas críticas encontradas na bibliografia especializada sobre o tema. Por fim, conclui-se pela existência da utilidade de seus postulados, qual seja, sua utilização como parâmetro para identificação de medidas autoritárias em meio ao sistema democrático.

\section{PALAVRAS-CHAVE}

Direito Penal do Inimigo. Política Criminal. Segurança Pública. Autoritarismo. Estado de Direito.

\section{ABSTRACT}

This work aims to discuss the instruments and problems related to implementation of a criminal policy based on the directives of the theory of Criminal Law of the Enemy, primarily developed by the German professor Günther Jakobs. Therefore, we discuss the feasibility and the practical limits of the government's role regarding the identification and nullification of risks, addressing the elements of the theory, then reviewing and debating its critical literature. Finally, this work acknowledges the usefulness of the theory of Criminal Law of the Enemy, that is, its use as a parameter of identification of authoritarian measures within the democratic system.

\section{KEYWORDS}

Criminal Law of the Enemy. Criminal Policy. Public Security. Authoritarianism. Rule of Law.

\section{SUMÁRIO}

Introdução. 1. A Teoria do Direito Penal do Inimigo e suas principais críticas. 2. Alguns apontamentos sobre o direito penal do inimigo. 2.1. O objeto da teoria do direito penal do inimigo. 2.2. O direito penal do inimigo como um direito penal do autor. 2.3. Sobre a neutralização do inimigo pelo Estado. Conclusão: uma utilidade à teoria do direito penal do inimigo. Referências.

\section{INTRODUÇÃO}

Esta apresentação propõe-se a expor e analisar a teoria do direito penal do inimigo (TDPI), seus desdobramentos teóricos e críticas habitualmente endereçadas a esta teoria, bem como sua viabilidade prática como instrumento de segurança pública. Não são poucas as questões de política de segurança pública que a envolvem, sejam diretamente relacionadas a direito penal ou a medidas administrativas; em síntese, ambas se tratam do exercício do poder do Estado em relação aos indivíduos.

\footnotetext{
* Professor de Direito Penal na graduação e pós-graduação da UERJ e da Escola de Direito da FGV/SP. Pós-doutor em Direito pelo Max Planck Institut, Alemanha. Doutor e Mestre em Direito Penal pela Universidade de São Paulo, com estágio doutoral na Humboldt Universität, Alemanha.

*** Mestre em Direito Penal pela UERJ. Pós-Graduado em Processo Penal e Garantias Fundamentais pela ABDConst.
} 
Não é à toa que o debate sobre relações entre um poder central e os indivíduos está presente desde o início da formação dos Estados modernos, como se costuma denominá-los. Destacadamente, percebe-se neste período a importância estrutural da pena (reação estatal), que se coloca como decorrência natural de um comportamento delituoso (ação individual) em favor da manutenção de uma ordem estatal. $\mathrm{O}$ despertar de transformadoras concepções na filosofia política e moral acarretaram paulatinamente reformulações políticas nas relações Estado $\leftarrow \rightarrow$ indivíduo e indivíduo $\leftarrow \rightarrow$ indivíduo ao longo da contemporaneidade; entretanto a concepção estruturante (uma relação de necessariedade) do binômio delito-pena tem resistido às referidas reformulações.

A importância da questão da pena gerou inúmeras construções teóricas sobre o direito e dever de punir e, mais tarde, o poder de punir e suas restrições. Atualmente, destacam-se duas correntes, que debatem acerca das diretrizes e alcances da política criminal, da criminologia e, de forma consequencial, da dogmática penal.

A primeira se diz minimalista ${ }^{1}$, deferente ao postulado iluminista da mínima interferência do direito penal na esfera individual (Kernstrafrecht); deste modo, entende possível a criminalização apenas de condutas que geram lesões a bens jurídicos de terceiros, perceptíveis sensorialmente, ou, excepcionalmente, que acarretam perceptível perigo a estes bens jurídicos. Ou seja, considera legítima a tutela penal de bens jurídicos individuais - como a vida, a liberdade, a propriedade privada; opõe-se aos tipos de perigo abstrato e à tipificação de atos preparatórios; isto é, exige que a descrição legal apenas alcance condutas que já estejam colocando em risco iminente o referido bem jurídico individual.
Portanto, fica nítida a importância que é atribuída, por esta corrente, a uma noção sensorial do delito. A construção do delito submisso a uma conduta naturalística, ontológica, pré-típica, que se liga a um resultado, também sensorialmente aferível, por meio de um nexo de causalidade sensível, limitaria a atividade punitiva a "direito penal do fato". A título de exemplo, esta corrente se coloca radicalmente em oposição a um conceito de conduta de matriz idealista, normativista, como, por exemplo, a construção de Gustav Radbruch (1904, pp. 43-83) da conduta como "ação típica" ou da conduta negativa, a que se atribui grande margem para o desenvolvimento de um "direito penal do autor"; isto porque a normativização da tipificação penal daria margem para a criminalização de estados e condições pessoais de existência, ultrapassando até mesmo a ideia de pena como reação.

Por sua vez, a segunda corrente é vinculada ao que se habitua chamar de moderno direito penal (Nebenstrafrecht), em um processo de expansão do direito penal. Por esta, a sociedade não é mais a mesma daquela existente nos tempos em que se desenvolveram as teorias a que se apegam os defensores do direito penal minimalista, de modo que o direito penal não pode estar estagnado no tempo sem acompanhar as novas necessidades na contemporaneidade.

Esta sociedade possui novos contornos decorrentes do desenvolvimento industrial e técnico-científico, de modo que há um deslocamento da atenção, antes voltada a lesões individuais, para atividades que colocam em risco toda uma coletividade. Como exemplo destas atividades, é possível mencionar algumas que são socialmente aceitáveis, mas que exigem um rigoroso controle estatal, como a gestão de energia nuclear, o extrativismo mineral, florestal e animal, além de atividades econômicas e financeiras.

${ }^{1}$ Destacam-se Luigi Ferrajoli (1995) e Alessandro Baratta (2004). 
Esta compreensão se forma a partir de uma ética consequencialista; em específico, um cálculo utilitário que coloca em oposição os benefícios e os prejuízos que determinadas atividades podem gerar a toda a coletividade. Naturalmente, esta relação entre necessidadeconsequência não é absoluta, mas, histórica, ao variar conforme a situação cultural e industrial específica de cada sociedade (JAKOBS, 2013, pp. 13-23).

Deste modo, pode-se falar que em relação a uma mesma atividade há alguns riscos que a coletividade $^{2}$ pode suportar e outros a que não se deve submeter; bem como atividades outras em que não há riscos suportáveis em função da inexistência de qualquer benefício proveniente, como o terrorismo.

Portanto, a esta segunda corrente, atividades complexas demandam regulamentações complexas, que podem, e devem, perpassar pela regulação penal da matéria, considerando a gravidade dos danos que podem resultar de determinadas atividades nesta sociedade de riscos.

Inúmeras são as questões de política criminal e dogmáticas postas em debate por esta corrente, algumas mais e outras menos defendidas, como a proteção de bens jurídicos coletivos ou supra individuais, a necessidade de tipos penais de perigo abstrato (presumido), a superação da culpabilidade baseada em um juízo de responsabilidade moral e a responsabilização penal da pessoa jurídica, além da administrativização do direito penal e sua internacionalização; ou seja, muitos elementos que normativizam categorias da teoria do delito.

Em síntese, pode-se dizer que ambas as correntes admitem transformações na sociedade que demandam novas orientações políticas de controle, entretanto divergem a respeito dos

\footnotetext{
${ }^{2}$ Destaca-se que a ideia de coletividade supera a noção de "Estados nacionais" típica do período oitocentista. Não se pode esquecer o papel estruturante do fenômeno da
}

meios de controle e proteção que devem ser empregados.

Enquanto a primeira corrente, apegada a uma tradição teórica, insiste na utilização de medidas alternativas - administrativas - quanto às inovações da sociedade de risco, a segunda corrente vê como natural a expansão do direito penal, não por ampliar um leque punitivista, mas, sim, por permitir que o direito penal alcance um determinado grupo de atividades tão ou ainda mais lesivas que aquelas tradicionalmente etiquetadas como delito pela sociedade.

Ambas ainda possuem em comum a concepção de um direito penal, seja de orientação "clássica" ou "moderna", fundado na existência de um mínimo de garantias dos indivíduos frente ao Estado, de modo que a persecução penal deve em todas as suas fases estar submetida aos princípios do Estado de direito, entendido em sua concepção substancial e não meramente formal, seja em decorrência de uma posição jus naturalista ou histórica.

Entretanto, nos últimos anos, uma política criminal bastante sui generis tem sido defendida, ainda que de maneira isolada, como meio de controle eficaz dos riscos a que tem estado submetida a sociedade: a TDPI, que, segundo GRACIA MARTÍN, seria "uma clara manifestação dos traços característicos do chamado Direito penal moderno" (2007, p. 76), porém de forma mais contundente e relativizando questões pacíficas dentre defensores do direito penal nuclear e do novo direito penal.

\section{A TEORIA DO DIREITO PENAL DO INIMIGO E SUAS PRINCIPAIS CRÍTICAS}

A TDPI envolve emocionalmente os debatedores de política criminal, de modo que por inúmeras vezes a discussão resta prejudicada,

globalização na sociedade de risco, como bem expõe Silva (SILVA SÁNCHEZ, 2013, p. 99 e ss.; GÓMES COLOMER, 2010, pp. 12 e ss.). 
inclusive a limitar a adequada compreensão da TDPI formulada por Jakobs e, consequencialmente, sua desconstrução.

Portanto, é imprescindível em primeiro lugar delimitar a teoria.

Jakobs sustenta uma tipologia dos criminosos conforme as relações que estes mantêm com o ordenamento jurídico e a sociedade, ao separar os indivíduos em sujeitos de direitos e deveres inseridos na ordem jurídica (seres humanos dotados de personalidade: pessoas) e indivíduos que se autocolocam a par (autoexclusão) da ordem jurídica (seres humanos não dotados de personalidade: inimigos).

Esta tipologia de Jakobs decorre de sua concepção de sociedade (sistema de comunicações) e, claro, do papel das normas jurídicas (instrumento de comunicação). Apoiado na compreensão de Luhmann de que o direito é um sistema social autopoiético, Jakobs interpreta e fundamenta sua construção na compreensão de que uma sociedade tem por objeto as comunicações e não indivíduos em si, com a conclusão de que a personalidade é uma atribuição jurídica em função das interações sociais (PORTILLA CONTRERAS, 2004, p.44); naturalmente, Jakobs também não concebe uma dogmática penal alheia às "interferências externas da sociedade" (JAKOBS, 2000, pp. 22-24).

O ponto fulcral é, portanto, a compreensão da alteridade pelo indivíduo. Esta compreensão é percebida com a passagem de um modelo de comportamentos orientados (voltados para/ visando a/ destinados a algo) exclusivamente por necessidades individuais (comunicação instrumental) (JAKOBS, 2000, p. 72) para um modelo em que a orientação comportamental do indivíduo é submetida a regras, a normas (comunicação pessoal), que podem afastar os indivíduos de suas necessidades-desejos.

\footnotetext{
3 “Os inimigos são Unpersonen. Esta negação da condição de pessoa é teoricamente sustentável só e enquanto se reconheça que esta, isto é, a personalidade, não é um dado
}

Isto significa que a "comunicação pessoal" ocorre quando o indivíduo atua (impelido) aquém ou além de suas necessidades individuais, ao perceber a si próprio como pessoa, bem como também perceber o outro indivíduo como pessoa (ou seja, que este também reconhece a si e o outro como dotados de personalidade) (JAKOBS, 2000, pp. 79-80), por ambos orientarem seu comportamento conforme a norma e, portanto, atenderem mutuamente suas expectativas de comportamento de acordo com o que determinam as normas.

É, portanto, um processo de mútuo reconhecimento, em que os indivíduos agem apoiando cognitivamente as normas, conferindo a elas vigência real (JAKOBS, 2012b, p. 56), sendo, portanto, reconhecidos pelo Direito como pessoas.

Ou seja, o indivíduo que age orientado pelas expectativas normativas é dotado de personalidade; enquanto aquele que age unicamente conforme sua orientação psíquica ( sistema psíquico, que reproduz a consciência, necessidades individuais — comunicação instrumental), sem apoiar cognitivamente as normas - negando sua vigência de forma habitual, desconsiderando a ordem — não é dotado de personalidade, não é pessoa (JAKOBS, 2000, pp. 79-81), em síntese: "um indivíduo que não admite ser obrigado a entrar em um estado de cidadania não pode participar dos benefícios do conceito de pessoa" (JAKOBS, 2012a, p. 35) ${ }^{3}$.

Deste modo, a norma (que, como visto, tem a função de orientar as condutas dos indivíduos) apenas é capaz de comunicar quais comportamentos são indesejados às pessoas, sendo impossível a comunicação às não-pessoas, por definição. Assim, surge a situação em que a expectativa quanto ao comportamento da nãopessoa é a não orientação conforme as

da natureza, mas, melhor, uma atribuição normativa de caráter moral, social e/ou jurídico" (PAVARINI, 2012, p. 173). 
expectativas normativas (JAKOBS, 2012b, p. 57), o que por certo coloca em risco a segurança dos indivíduos que se orientam conforme a norma, visto que é, justamente, a proteção de bens da vida frente a riscos o papel da norma (JAKOBS, 2012a, p. 40).

Portanto, considerando esta premissa, Jakobs conclui pela existência de duas espécies de perigo e, portanto, duas espécies de atuações diversas em relação a estes perigos, alcançando o que diferencia entre direito penal do cidadão e DPI.

O direito penal do cidadão é aquele voltado a pessoas. Pergunta-se: é possível uma pessoa cometer um delito na concepção de Jakobs? Sim. Isto porque um indivíduo pode contrariar uma norma penal sem que esteja negando a ordem jurídica e social, pois "o ato não se dirige contra a permanência do Estado, e nem sequer contra a [permanência] de suas instituições", mas apenas danifica a vigência da norma, devendo esta ser equilibrada por meio da sanção, da pena (JAKOBS, 2012a, p. 31) - função preventiva geral positiva -, considerando que a pena é forma de comunicação, um meio de interação simbólica (JAKOBS, 2008, p. 22).

Ou seja, ao cidadão, por não colocar em sério risco a ordem jurídica e social, é possível, e devida, a incidência de amplos direitos e garantias. Tem-se um direito penal do fato, que apenas pode atuar reativamente - e não preventivamente -, conferindo ao cidadão amplas garantias processuais de defesa.

Por sua vez, no que toca à não-pessoa (inimigo) o que se tem é a constante iminência de um grave dano, de modo que o dever do Estado é neutralizar este perigo à segurança dos demais

\footnotetext{
${ }^{4}$ Por exemplo: CUSSAC, 2007, p. 52; FEIJOO

SÁNCHEZ, 2007, pp. 104-7; MUÑOZ CONDE, 2012, pp. 65-68; AMBOS, 2007, pp. 17-29; CANCIO MELIÁ, 2012, pp. 92-93.

${ }^{5}$ Neste sentido: ZAFFARONI, 2011, p. 159; PAVARINI, M, 2012, p. 176.

${ }^{6}$ É interessante observar o tom elogioso de Zaffaroni a

Jakobs quanto a TDPI, isto pois aquele afirma que o
}

indivíduos. Ou seja, o Estado constata um perigo (periculosidade do sistema-psíquico) e atua preventivamente, em uma luta/guerra contra o inimigo (JAKOBS, 2012b, p. 62), com o intuito de proteção e segurança dos cidadãos. A resposta do Estado não é pena - não tem função comunicativa (ainda que possa ter colateralmente) — é simplesmente medida de segurança, esforço de luta/guerra, contenção (JAKOBS, 2012a, p. 23).

E, por fim, Jakobs elenca aqueles criminosos que não estão alinhados cognitivamente ao sistema: naturalmente, aqueles que atuam em organizações criminosas como um todo, a criminalidade econômica, sexual e, em especial, o terrorismo (Jakobs, 2012a, p. 34).

Como tem sido discutido, com duras críticas a um pretenso descritivismo ${ }^{4}$, Jakobs não defende explicitamente uma política criminal baseada no DPI, mas em alguns momentos tomaa como descrição de uma política criminal já em curso e em outros parece afirmá-la como inevitável e imperiosa; esta última parece ser sua real posição ${ }^{5}$. O certo é que Jakobs diferencia, e com razão ao menos em um sentido descritivo, um direito penal com elementos dos tipos ideais "direito penal do cidadão" e "direito penal do inimigo", de modo que aquele contém elementos de ambos os tipos ideais sem uma adequada distinção. Isto acarreta uma confusão que contamina todo o direito penal, submetendo "pessoas" a tratamentos conferíveis a "nãopessoas", de modo que uma delimitação clara seria necessária para superar este problema (JAKOBS, 2012a, p. 21;47) ${ }^{6}$.

Com isto, expõe-se brevemente as principais críticas dirigidas à TDPI.

tratamento de guerra é naturalizado nas agências de controle e racionalizado pelo discurso penal, de modo que Jakobs teria exposto cruamente a situação e elaborou uma proposta "da mais absoluta boa fé quanto ao futuro do Estado constitucional de direito" (ZAFFARONI, 2011, pp. 157-159). 
Certamente, não são poucas as críticas negativas à construção de Jakobs, de modo que esta parece ser apoiada apenas por alguns de seus discípulos (FEIJOO SÁNCHEZ, 2007, p. 104107; PORTILLA CONTRERAS, 2004, passim). As referidas críticas podem ser separadas conforme pontos específicos, mas todos eles se entrelaçam por estarem em um mesmo plano ou paradigma teórico.

A primeira grande crítica é feita em função da normativização da condição de pessoa na teoria de Jakobs. Segundo seus críticos, atenta contra o princípio dominante da dignidade da pessoa humana e está absolutamente em oposição à noção de Estado democrático de direito ${ }^{7}$; esta é possivelmente a crítica com maior ocorrência na doutrina, inclusive por seu efeito guarda-chuva em relação à maioria das demais.

Entretanto, vale a observação de que o princípio da dignidade da pessoa humana, apesar de recorrentemente utilizado para atacar este quadro desenhado, certamente não embasa um bom argumento. Como bem salienta GRACIA MARTÍN, Jakobs e os críticos partem de premissas diversas: enquanto o primeiro elabora um perfil normativo da personalidade (por sinal, como o faz também a construção de tradição milenar do direito privado); os críticos identificam "a pessoa como homem, como indivíduo humano" (2007, p. 163). Além disto, a dignidade da pessoa humana é também um conceito normativo, e, ainda assim, de tão amplo espectro que resulta um conceito vazio, um nãoconceito. E, de qualquer forma, seria possível argumentar que tal dignidade, como o próprio nome diz, é atributo de pessoa; não de inimigo -

\footnotetext{
${ }^{7}$ Por exemplo: CUSSAC, 2007, p. 58; FEIJOO SÁNCHEZ, 2007, p. 102; MUÑOZ CONDE2012, p. 33; GÓMES COLOMER, 2010, p. 21; GÖSSEL, 2007, p. 96; AMBOS, 2007, pp. 20-21; ALBRECHT, 2010, p. 118; GRACIA MARTÍN, 2007, p. 171-177; ZAFFARONI, 2011, pp. 159;163-165; DEMÉTRIO CRESPO, 2009a, p. 47.
}

exsurge um efeito da divergência nas premissas observada por Gracia Martín.

De todo modo, são inúmeras as acusações de um autoritarismo reformado ${ }^{8}$, de uma tentativa de inserção de uma prática institucionalizada de Estados absolutos no seio dos Estados democráticos contemporâneos, desvirtuando politicamente o direito penal ao ponto de transformá-lo em um não direito penal, uma autonegação, uma contradição em seus termos (FERRAJOLI, 2006, p. 798; ALBRECHT, 2010, p. 117; CANCIO MELIÁ, 2007, p. 74); criando um verdadeiro estado de exceção permanente (CARVALHO, 2007, p. 170-173) em decorrência de uma perene emergência (SILVA SÁNCHEZ, 2013, p. 197).

Ainda, são comuns as acusações de que a TDPI legitima em absoluto um direito penal do autor ${ }^{9}$, também incompatível com o direito penal de um Estado democrático de direito, ao ponto de se apontar como um auto aniquilamento a inserção do DPI em um ordenamento jurídico (GOMES-JÁRA DÍEZ, 2007, pp. 53-4).

MUÑOZ CONDE relaciona diretamente a TDPI ao sistema penal do nacional-socialismo e à contribuição de Mezger ao projeto relativo ao tratamento dos "estranhos à comunidade" (Gemeinschaftsfremde) (2005, pp. 113-146). Chega a afirmar ser injusto atribuir autoria a Jakobs, pela existência de inúmeras "construções análogas e com o mesmo significado políticojurídico", em especial na primeira metade do século XX (2010, p. 143); entretanto também seria possível mencionar a bem mais recente distinção descritiva de GARLAND entre "criminology of the self", do "nós", e "criminology of the other", própria dos

\footnotetext{
${ }^{8}$ A título de exemplo: MUÑOZ CONDE, 2012, p. 32; CANCIO MELIÁ, 2007, pp. 92-93. CUSSAC afirma ser um "autoritarismo [puramente] político" (2007, p. 57). ${ }^{9}$ Por exemplo: CUSSAC, 2007, p. 67; DÍEZ RIPOLLÉS, 2005, p. 21; GRACIA MARTÍN, 2007, p. 132; CANCIO MELIÁ, 2012, pp. 108-109; ZAFFARONI, 2011, p. 116; DEMÉTRIO CRESPO, 2009a, pp. 47-48.
} 
estrangeiros perigosos, do temido desconhecido, dos excluídos, dos diferentes (1996, p. 461).

Por fim, vale lembrar as duras críticas de Albrecht ao que denomina "direito penal póspreventivo", que, partindo de um paradigma diametralmente oposto de sociedade, considera a TDPI como corolário da supremacia da segurança sobre a liberdade em um processo de aniquilação do direito, visto que este não mais serviria eficientemente a um programa de controle e dominação $(2010 \text {, pp. } 97 ; 107 ; 112-115)^{10}$.

\section{ALGUNS APONTAMENTOS SOBRE O DIREITO PENAL DO INIMIGO}

Exposta a TDPI e, de forma sucinta, as principais críticas que lhe são dirigidas, é possível, de forma breve em função da natureza desta exposição, elaborar algumas reflexões.

\subsection{O objeto da teoria do Direito Penal do Inimigo}

É corriqueira a referência à TDPI como um instrumento de política criminal voltado ao combate de crime organizado e de terrorismo. Entretanto, ainda que Jakobs utilize estes exemplos para sua exposição, sua construção teórica não "proporciona/é capaz" de uma limitação material.

Se o que identifica um inimigo é o risco que oferece e este risco se configura em decorrência da não orientação conforme as expectativas normativas, não importa qual o resultado (natureza/espécie de ação) de sua orientação cognitiva; basta, em síntese, a expectativa de não orientação conforme as expectativas normativas. É claro que é possível falar em graus diversos de riscos, mas esta é uma discussão para o âmbito da resposta do Estado, não para a configuração de

\footnotetext{
${ }^{10}$ Também sobre esta tensão entre liberdade e segurança: DEMÉTRIO CRESPO, 2009b, passim; DÍEZ RIPOLLÉS fala que entramos "en una dinámica que tiende a superar el
}

um inimigo. Isto fica evidente a partir da constatação do próprio Jakobs, como supra referido, de que a sujeição e a aceitação de riscos variam conforme a sociedade concreta, ou seja, variam conforme sua localização histórica.

Assim, por exemplo, em uma sociedade em que acender um cigarro em local público é um risco inaceitável para toda uma coletividade em decorrência de alguma alteração química, de modo que a norma comunica aos indivíduos acerca desta restrição social, o indivíduo que o faria/faz em âmbito de uma autoexclusão representa um perigo que deve o Estado conter.

A utilização de certos fatos, como "terrorismo" por exemplo, parece decorrer apenas de que são, neste momento, o ponto sensível da questão de segurança em diversos países, portanto, seriam nessas sociedades historicamente localizadas objeto inserível na TDPI - o que, como dito, não faz, por ex., do terrorismo um objeto necessário de inserção (tempo e espaço) na teoria, visto que sequer é uma realidade verificável em tempos atuais por todo o espaço.

Desta conclusão é possível perceber um sério problema de coerência desta teoria quanto a seu tipo ideal: como a sociedade percebe um indivíduo que não se orienta conforme as expectativas normativas para lutar contra este inimigo/risco? Não seria possível esperar a atuação lesiva, a considerar que o escopo é justamente evitá-la. Inúmeras podem ser as conjecturas para sanar o problema - que à primeira vista parece ser apenas superável, na praxis, por um autoritarismo decisionista.

Portanto, parece haver um problema estrutural na TDPI em sua concepção: a necessária subversão de sua estrutura.

Como visto, o inimigo é, em decorrência da teoria da personalidade utilizada por Jakobs, um risco independentemente de qualquer dano

hace poco indiscutido modelo penal garantista y a sustituilo por outro al que he denominado el modelo penal de la seguridad ciudadana” (2005, p. 2). 
efetivo ou perigo de dano concreto, bem como independente de um objeto material específico (o rótulo do risco é "inimigo"; não, inimigo que incute o terror ou inimigo que comete homicídios etc). Considerando que é papel do Estado neutralizar este risco - decorrente da autoexclusão —- percebe-se que deve: a) perceber o risco/inimigo; b) neutralizar o risco/inimigo; c) evitar o dano.

Como não é possível que o Estado perceba o desvio de orientação (auto exclusão) de um indivíduo imediatamente, por não existir um elemento objetivo, ôntico, que naturalize a condição de "não-pessoa/risco/inimigo", apenas será possível perceber o inimigo por meio de suas ações (externas, claro); necessariamente, estas ações (preparatórias, no caso de um inimigo) não podem ser a realização do dano, sob pena de fracasso ab ovo do intento neutralizante; bem como não podem ser a colocação direta em perigo do bem da vida, pois neste caso a TDPI restaria desnecessária, considerando os tipos de perigo concreto.

Ou seja, estas ações (preparatórias) que permitem a percepção pelo Estado de um inimigo são ações confundíveis com ações de "pessoas/amigos" que não são/oferecem qualquer risco.

Pergunta-se: como o Estado diferenciará a pessoa da não-pessoa se o único meio de o fazer se dá por indícios advindos de ações não danosas/perigosas em si, mas que são realizadas pelo inimigo que atua em espectro amplo (considerando o conjunto de ações de seu intento) em descompasso com as expectativas normativas? Necessariamente, o Estado etiquetará, criará, o inimigo, ou seja; decidirá quem será aquele percebido como inimigo. Isto porque, como visto, elementos externos ao indivíduo é que permitirão ao Estado reconhecer um indivíduo como inimigo.

Logo, o caminho que o Estado irá percorrer é: a) percepção de uma ação que indique uma potencial condição de inimigo de um indivíduo; b) alcance/neutralização deste indivíduo; c) percebe (decide) se é ou não de fato um inimigo.

Deste modo, vê-se que a neutralização não é apenas de inimigos (inimigos reais), mas também daqueles que o Estado perceber, ainda que não o sejam, como inimigos (inimigos fictícios, etiquetados). É o que também fora percebido por SALIGER, que analisa este quadro como um etiquetamento desde uma fundamentação subjetiva (2007, p. 81); e, como aponta APONTE CARDONA, não é difícil vislumbrar o carrossel de problemas decorrente de expectativas normativas e decisionismo institucional em sociedades multiculturais como, por exemplo, as latino-americanas (2005, p. 495), com o passado apontando inúmeros contornos deste quadro.

Certamente o Estado conseguirá neutralizar inimigos e evitar danos, como também necessariamente tratará pessoas como nãopessoas, justamente o que Jakobs considera objetivo principal evitar: a utilização de medidas típicas de DPI quanto a "pessoas" (indivíduos orientados conforme as expectativas normativas sejam ou não infratores).

$\mathrm{Ou}$ seja, mais do que proporcionar segurança, a busca estatal por inimigos em realidade será um grande risco à segurança de toda a coletividade de indivíduos, das "pessoas".

Portanto, parece que a única situação segura para uma percepção adequada de um inimigo é o caso da habitualidade ou reiteração criminosa. Nestes casos, uma série de atos reflete objetivamente a condição de não-pessoa do indivíduo. Entretanto, se o objetivo da TDPI é justamente evitar sérios danos, seria uma contradição em seus próprios termos apenas estar em um campo seguro de atuação após inúmeros danos.

Em conclusão: se de fato esta é uma teoria propositiva: parece contraditória em seus próprios termos e, portanto, ineficiente, até mesmo 
contraproducente; se é descritiva: não há como discordar de que se trata de um caminho autoritário e completamente a parte de um estado democrático de direito, em que possa estar inserida.

\subsection{O Direito Penal do Inimigo como um Direito Penal do autor}

Pelo exposto, parece claro que o ponto central da teoria não é a especificidade da norma violada ou do bem da vida posto em perigo, mas, sim, a condição "não-pessoal" do inimigo; pois o papel do Estado é enfrentar, lutar, combater, o indivíduo perigoso, que é um risco, seja qual for a decorrência material deste risco.

Logo, não há como discordar da afirmação de que o DPI é, por definição, direito penal do autor, o que não é um problema teórico, mas sim um elemento estrutural e, portanto, indispensável. Entretanto, não parece adequada a relação feita por Muñoz Conde, que relaciona diretamente esta teoria ao tratamento dado pelo NacionalSocialismo aos "estranhos à comunidade". Isto porque é indiscutível que este partia de premissas diversas, ainda que o texto dos projetos trabalhe explicitamente com a ideia de inadequada condução de vida.

Para chegar a esta conclusão, de forma bastante resumida, é possível utilizar a análise de ZAFFARONI acerca de um inimigo constituído em decorrência de elementos objetivos, naturais, ônticos; e é justamente este o inimigo (pessoa, mas tratado conforme sua periculosidade) na construção do positivismo criminológico (2011, p. 93). Tem-se um inimigo claramente definido, perceptível sensorialmente; deste modo, não se enfrenta a paradoxal capacidade de percepção do inimigo a que conduz a TDPI.

Como bem afirma ZAFFARONI, o Nacional-Socialismo serviu-se sobremaneira destes elementos ônticos na configuração de seus inimigos, levando ao extremo o positivismo criminológico (2011, pp. 104-106); a TDPI servese da autoexclusão, decisão individual, de indivíduos de se tornarem inimigos, independentemente de quaisquer outras características; ao ponto de, como exposto, Zaffaroni reconhecer a, sem utilizar este conceito, "boa vontade" de Jakobs, ainda que seja possível reconhecer seu caráter autoritário (GRECO, 2005, p. 230).

\subsection{Sobre a neutralização do inimigo pelo Estado}

Considerando o exposto, é possível alcançar a importante questão da "pena" no DPI.

Em conformidade com o que defendem Ferrajoli, Cancio Meliá e Albrecht, em destaque, não é possível entender o DPI como direito penal, de modo que esta constatação gera sérios reflexos à natureza da atuação do Estado contra o risco/inimigo; o que se passa a expor.

Esta atuação, sob a TDPI, deve ser vista sob dois ângulos: a) do Estado e da sociedade; b) do sistema psíquico destinatário.

Preliminarmente, é imperioso esclarecer que não se trata de uma "resposta estatal" ou "reação", mas sim de uma ação estatal, uma intervenção, justamente por sua natureza de atuação preventiva; apenas pode ser considerada resposta/reação se se pensar o início da orientação, desconforme às expectativas, de comportamentos do indivíduo como "ação", o que não merece acolhida.

Ainda que haja dois ângulos bastante bem delineados, não é necessário expô-los separadamente, visto que são os lados de uma mesma moeda. Acerca disto, nota-se o seguinte.

A considerar que o objetivo do Estado é unicamente a segurança do sistema frente a um risco, sua atuação preventiva é beligerante, de luta, justamente em decorrência da impossibilidade de comunicação por meio das normas com o inimigo. Este inimigo, como não- 
pessoa, não é sujeito de direito, de modo que não está o Estado limitado a atuar conforme as garantias processuais e materiais relativas a ele impostas pelo direito processual e penal.

Como não-pessoa, é equiparado a qualquer outro objeto-não-pessoa, coisa perigosa. Como exemplo, um meteoro que está na iminência de cair em uma metrópole é uma coisa perigosa, a que o Estado deve combater de todas as formas com o fim de proteção e segurança; o mesmo se uma horda de animais silvestres e ferozes invade uma área repleta de pessoas indefesas, é dever do Estado eliminar o perigo; da mesma forma, quando um sistema-psíquico/inimigo é a fonte de risco $^{11}$.

Isto, entretanto, não implica que o Estado atuará da forma mais drástica, devendo sopesar o caso concreto de acordo com a necessidade e adequação de sua medida de segurança. A noção de estado de direito demanda um grande conjunto de regulações da atuação estatal e em relação ao combate do inimigo não há como ser diferente. Logo, é impossível falar em "não direito", pois o Estado apenas age de forma legítima se atua confirme a ordem normativa, inclusive em âmbito externo no que se refere ao direito internacional de guerra (NEUMANN, 2007, p. 164; MUÑOZ CONDE, 2010, pp. 149-150).

APORTE CARDENAS, por sua vez, interpreta que a opção por medidas mais (menor submissão ao direito) ou menos drásticas (maior submissão ao direito) seria fundamentada na distinção entre "inimigos relativos" e "inimigos absolutos" (2005, p. 499). Esta visão se mostraria acertada ao se pensar unicamente em nível de garantias do indivíduo, entretanto não faz sentido a se considerar o que preconiza a teoria, ou seja, a efetividade, submetida apenas à regulamentação formal administrativa.

\footnotetext{
${ }^{11}$ Percebe-se em Jakobs a preocupação com a conciliação devida entre uma atuação estatal sob bases legais e a efetividade da atuação no âmbito do direito penal (2004, p.
}

Isto porque, ainda que se trate de um "não direito penal", trata-se de direito: um "direito administrativo"; poder de polícia em sentido estrito; possivelmente com limitações de direito internacional humanitário. Este direito administrativo não tem o escopo de proteção do destinatário da resposta, mas sim de garantir os interesses das "pessoas" e do próprio Estado.

Ao considerar o exposto, fica claro que a atuação do Estado sob o "direito penal do inimigo" é de um controle interventivo neutralizador, de regulação administrativa; sendo incompatível com a ideia de que a pena deve ser condicionada à condição de pessoa do indivíduo, ou seja, à "dignidade da pessoa humana".

\section{CONCLUSÃO: UMA UTILIDADE À TEORIA DO DIREITO PENAL DO INIMIGO}

Enfim, a considerar todo o exposto, pode-se afirmar que a TDPI não é uma teoria do direito propriamente dita, mas sim de uma teoria de ciência e/ou filosofia política.

Esta teoria foi apenas esboçada, não houve um desenvolvimento meticuloso, como é possível perceber, e isto pode ser um elemento que corrobore a tese de que a posição de Jakobs é de descrição em vez de afirmação.

Não obstante toda a crítica elaborada, predominantemente negativa, é possível perceber que a teoria pode contribuir em âmbito de segurança pública sendo utilizada para identificar elementos autoritários incompatíveis com a ordem jurídica em debate, conforme a defesa de Jakobs de inexistência de um sistema de direito

41). Logo, parece que a medida tomada frente ao inimigo teria como limite a efetividade; Jakobs em algumas passagens denota uma limitação neste agir do Estado. 
penal puro (alinhado integralmente a algum dos dois tipos ideais $)^{12} 13$.

\section{REFERÊNCIAS}

ALBRECHT, P. A. Criminologia: uma fundamentação para o direito penal. Trad. Juarez Cirino dos Santos, Helena Schiessl Cardoso. Curitiba: ICPC; Rio de Janeiro: Lumen Juris, 2010.

AMBOS, K. Direito penal do inimigo. Panóptica - Direito, Sociedade e Cultura, FDV, Vitória, v. 2, n. 7, pp. 1-45, 2007.

APONTE CARDONA, A. Derecho penal de enemigo vs. derecho penal del ciudadano: Günther Jakobs y los avatares de un derecho penal de la enemistad. Cuadernos de doctrina y jurisprudencia penal, Buenos Aires, v. 10, n. 18/19, pp. 481-512, 2005.

BARATTA, A. Principios de derecho penal mínimo. In: BARATTA, A. Criminología y sistema penal (compilación in memorian). Buenos Aires: Editorial B de F, pp. 299-333, 2004.

CANCIO MELIÁ, M. De novo: “Direito penal do inimigo?”. In: JAKOBS, G; CACIO MELIÁ. M. Direito penal do inimigo: noções e críticas. Trad. e org. André Luís Callegari, Nereu José Giacomolli. 6a ed. Porto Alegre: Livraria do Advogado, pp. 71-118, 2012.

CARVALHO, S. de. A política de guerra às drogas na América Latina entre o direito penal do inimigo e o estado de exceção permanente. Revista Panóptica - Direito, Sociedade e Cultura, FDV, Vitória, v. 2, n. 7, pp. 164-177, 2007.

CUSSAC, J. L. G. El renacimiento del pensamiento totalitario en el seno del estado de Derecho: la doctrina del derecho penal enemigo. Revista Penal, La Ley, Madri, n. 19, pp. 52-69, 2007.

DEMÉTRIO CRESPO, E. Del « derecho penal liberal » al «derecho penal del enemigo ». Quid Iuris, UNAM, Cidade do México, ano 4, v. 10, pp. 45-81, set. 2009a.

DEMÉTRIO CRESPO, E. El « derecho penal del enemigo » darf nicht sein! Sobre La ilegitimidad del llamado "derecho penal del enemigo" y La Idea de seguridad. Quid Iuris, UNAM, Cidade do México, ano 4, vol. 10, pp. 83-114, set./2009b.

DÍEZ RIPOLLÉS, J. L. De la sociedad del riesgo a la seguridad ciudadana: un debate desenfocado. Revista Electrónica de Ciencia Penal y Criminología (RECPC), Granada, n. 07-01, pp. 1-37, 2005. Disponível em: 〈http://criminet.ugr.es/recpc/07/recpc07-01.pdf〉. Acesso em: 09 nov. 2014.

FEIJOO SÁNCHEZ, B. O direito penal do inimigo e o Estado Democrático de Direito. Revista Panóptica - Direito, Sociedade e Cultura, FDV, Vitória, v. 2, n. 7, pp. 100-134, 2007.

FERRAJOLI, L. Derecho y razón. Teoría del garantismo penal. Tradução de Percto Andrés Ibáñez, Alfonso Ruiz Miguel, Juan Carlos Bayón Mohino, Juan Terradillos Basoco, Rocío Cantarero Bandrés. Madri: Editorial Trotta, 1995.

\footnotetext{
${ }^{12}$ Neste sentido, por exemplo: NEUMANN, 2007, p. 176.

${ }^{13}$ PRITTWITZ, entretanto, afirma que o "direito penal

como um todo está infectado pelo direito penal do inimigo;
}

[que] é totalmente impensável a reforma de uma parte do direito penal para voltar a um direito penal do cidadão realmente digno de um Estado de Direito" (2004, p. 43). 
. Il «diritto penale del nemico» e La dissoluzione del diritto penale. Questione giustizia, Franco Angeli Edizioni, Milão, n. 4, pp. 797-812, 2006.

GARLAND, D. The limits of the sovereign state: strategies of crime control in contemporary society. The British Journal of Criminology, v. 36, n. 4, pp. 445-471, out. 1996.

GÓMES COLOMER, J. Dogmática penal y proceso penal, algunas disfuncionalidades relevantes de la actualidad. Cuadernos de derecho penal. Universidad Sergio Arboleda, Bogotá, n. 3, pp. 9-36, 2010.

GÓMEZ-JARA DÍEZ, C. Normatividad del ciudadano versus facticidad del enemigo: crítica al fundamento científico del derecho penal del enemigo. Revista de Estudos Criminais, Porto Alegre, v. 7, n. 24, pp. 33-54, jan./mar. 2007.

GÖSSEL, Karl Heinz. Réplica del Derecho Penal del Enemigo. Sobre seres humanos, indivíduos y personas del derecho. Revista Penal, La Ley, Madri, n. 20, pp. 89-100, 2007.

GRACIA MARTÍN, L. O horizonte do finalismo e o direito penal do inimigo. Trad. Luiz Regis Prado, Érika Mendes de Carvalho. São Paulo: Editora Revista dos Tribunais, 2007.

GRECO, L. Sobre o chamado direito penal do inimigo. Revista da Faculdade de Direito de Campos, Campos, Rio de Janeiro, ano VI, n. 7, pp. 211-224, dez. 2005.

JAKOBS, G. A imputação objetiva no Direito Penal. Trad. André Luís Callegari. 4a ed. São Paulo: Editora Revista dos Tribunais, 2013.

. Direito penal do cidadão e direito penal do inimigo. In: JAKOBS, G; CACIO MELIÁ. M. Direito penal do inimigo: noções e críticas. Trad. e org. André Luís Callegari, Nereu José Giacomolli. $6^{\mathrm{a}}$ ed. pp. 19-48. Porto Alegre: Livraria do Advogado, 2012.

2004.

. Dogmática de derecho penal y la configuración normativa de la sociedad. Civitas Ediciones,

. Terroristas como Pessoas de Direito?. In: JAKOBS, G; CACIO MELIÁ. M. Direito penal do inimigo: noções e críticas. Trad. e org. André Luís Callegari, Nereu José Giacomolli. 6 ${ }^{\mathrm{a}}$ ed. Porto Alegre: Livraria do Advogado, 2012.

. Tratado de Direito Penal: teoria do injusto penal e culpabilidade. Trad. Gercélia Batista de Oliveira Mendes e Geraldo de Carvalho. Belo Horizonte: Del Rey, 2008.

. Sociedad, norma y persona en una teoría de un derecho penal funcional. Trad. Manuel Cancio Meliá, Bernardo Feijóo Sánchez. Madri: Civitas Ediciones, 2000.

MUÑOZ CONDE, F. Direito penal do inimigo. Tradução de Karyna Batista Sposato. Curitiba: Juruá, 2012.

Edmund Mezger e o direito penal de seu tempo: estudos sobre o direito penal no NacionalSocialismo. 4a ed. Trad. Paulo César Busato. Rio de Janeiro: Lumen Juris, 2005. 
. Los orígenes ideológicos del derecho penal del enemigo. Revista Penal, Valencia, n. 26, pp. 139-150, jul. 2010.

NEUMANN, U. Direito penal do inimigo. Tradução de Antonio Martins. Revista Brasileira de Ciências Criminais, São Paulo, n. 69, v. 15, pp. 156-178, 2007.

PAVARINI, M. Punir os inimigos: criminalidade, exclusão e insegurança. Trad. Juarez Cirino dos Santos, Aliana Cirino Simon. Curitiba: LedZe Editora, 2012.

PORTILLA CONTRERAS, G. Fundamentos teóricos del derecho penal y procesal-penal del enemigo. Jueces para La democracia: información y debate, Editorial Trotta, Madri, n. 49, pp. 43-50, mar. 2004.

PRITTWITZ, C. O direito penal entre direito penal do risco e direito penal do inimigo: tendências atuais em direito penal e política. Tradução de Helga Sabotta de Araújo e Carina Quito. Revista Brasileira de Ciências Criminais, São Paulo, n. 47, v. 12, pp. 31-45, 2004.

RADBRUCH, G. Der Handlungsbegriff in seiner Bedeutung für das Strafrechtssystem. Zugleich ein Beitrag zur Lehre von der rechtswissenschaftlichen Systematik. Berlin: J. Guttentag Verlagsbuchhandlung, 1904.

SALIGER, F. El derecho penal del enemigo: um concepto crítico o totalitário del derecho penal. Trad. Edgardo Alberto Donna. Revista de Derecho Penal, Buenos Aires, n. ${ }^{\circ}$ 1, 2007, pp. 69-87.

SILVA SÁNCHEZ. J. A expansão do direito penal: aspectos da política criminal nas sociedades pósindustriais. Trad. Luiz Otavio de Oliveira Rocha. $3^{\text {a }}$ ed. São Paulo: Editora Revista dos Tribunais, 2013.

ZAFFARONI. E. R. O inimigo no direito penal. $3^{\text {a }}$ ed. Trad. Sérgio Lamarão. Rio de Janeiro: Revan, 2011. 
